\title{
Automotive timing belt life laws and a user design guide
}

\author{
T H C Childs ${ }^{1}$, K W Dalgarno ${ }^{1}$, A J Day ${ }^{2}$ and R B Moore ${ }^{2}$ \\ ${ }^{1}$ Department of Mechanical Engineering, University of Leeds \\ ${ }^{2}$ Department of Mechanical and Manufacturing Engineering, University of Bradford
}

\begin{abstract}
The paper presents a computer-based guide of the effect of layout and loading (tension and torque) on the timing belt life and uses it to show the sensitivity of life to changed conditions in an automotive camshaft drive. The predictions are in line with experience. The guide requires belt property information, such as the tooth and tension member stiffness, the friction coefficient between the belt lands and pulleys and the pitch difference from the pulley, in order to calculate the tooth deflections caused by the belt loadings on the various pulleys in the layout. It also requires information on how the belt life depends on the tooth deflections. Experimental data are presented on the life-deflection relations of a commercial automotive timing belt tested between 100 and $140{ }^{\circ} \mathrm{C}$, although the bulk of the data has been obtained at $120^{\circ} \mathrm{C}$. Four different life laws have been found, depending on whether the failure-initiating deflection occurred on a driver or a driven pulley, and whether at entry to or exit from the pulley. Theoretical analysis of the tooth loading in the partial meshing state shows that, in three cases out of the four, the different life-deflection laws transform to a single relation between the life and the tooth root strain. The exception is failure caused by driven entry conditions; work is continuing to understand better the causes of failure in this circumstance.
\end{abstract}

Keywords: belts, camshaft drives, fatigue life, design

\section{NOTATION}

$A, B, A^{*}, B^{*}$
$F$
$K_{\mathrm{b}}$
$K_{\mathrm{t}}$
$L$
$P_{\mathrm{b}}$
$P_{\mathrm{p}}$
$Q$
$R_{\mathrm{p}}$
$t_{\mathrm{d}}$
$t_{\mathrm{w}}$
$T, T^{\prime}$
$V_{\mathrm{b}}$
$V_{\mathrm{p}}$

$\delta$
$\theta_{1}$
$\lambda$
$\mu$
$\Psi$

\author{
constants in life equations (1) \\ land frictional force $(\mathrm{N})$ \\ belt extension stiffness $(\mathrm{N} / \mathrm{mm})$ \\ tooth stiffness $(\mathrm{N} / \mathrm{mm})$ \\ tooth life (loading cycles to failure) \\ belt pitch $(\mathrm{mm})$ \\ pulley pitch $(\mathrm{mm})$ \\ tooth load $(\mathrm{N})$ \\ pulley pitch radius $(\mathrm{mm})$ \\ tooth depth $(\mathrm{mm})$ \\ tooth width $(\mathrm{mm})$ \\ belt tensions $(\mathrm{N})$ \\ belt velocity $(\mathrm{mm} / \mathrm{s})$ \\ pitch line pulley velocity $(\mathrm{mm} / \mathrm{s})$
}

$= \pm 1$

pulley land angular extent (rad)

tooth deflection $(\mathrm{mm})$

friction coefficient

tooth root strain parameter [equation (8)]

The MS was received on 10 June 1997 and was accepted for publication on 10 November 1997.

\section{INTRODUCTION}

This paper extends a series [1-5] which reports on tooth root cracking failures of automotive timing belts, studied experimentally by elevated-temperature $\left(100-140{ }^{\circ} \mathrm{C}\right)$ torque transmission tests on a laboratory dynamometer and theoretically by both classical mechanics and finite element modelling. Here, the experimentally established life laws are reported for failures generated on both driving and driven pulleys, and in seating (entry) and unseating (exit) conditions; these are incorporated in a computer-based design guide to predict effects of belt loading and layout on the life of camshaft drive belts.

It is well established from dynamometer studies in which torque is transmitted between two equal sized pulleys that, at least for lives of from 0.1 to 10 million tooth loading cycles, linear relations exist between torque transmission and $\log ($ life); modelling of the load sharing between teeth in fully meshed conditions allows these to be interpreted as linear relations between tooth deflection, $\lambda$, and $\log (\operatorname{life})$ $[1,3,6]$. For any one belt (with a particular tooth stiffness) there is a one-to-one relation between tooth deflection and tooth load, $Q$; so the life may also be related to the tooth load. It is convenient to express the life as multiples of $10^{6}$ 
tooth loading cycles, to write alternative forms of the life law as

$$
\begin{aligned}
& \lambda=A-B \log \left(\frac{\text { life }}{10^{6}}\right) \\
& Q=A^{*}-B^{*} \log \left(\frac{\text { life }}{10^{6}}\right)
\end{aligned}
$$

However, when life is determined by the tooth deflection at entry to the driver pulley, the coefficients $A$ and $B$ differ from the coefficients when it is tooth deflection at driven exit that governs life. Figure 1a, reproduced for convenience from reference [4], shows the life laws established for a curvilinear toothed belt nominally of $9.525 \mathrm{~mm}$ pitch transmitting torque between two 19-toothed pulleys at an ambient temperature of $100{ }^{\circ} \mathrm{C}$. The driven exit life relation falls below that established for driver entry failures. Recently, as reviewed briefly in Subsection 2.1, it has been shown that a unified life law for driver entry and driven exit failures can be created if the life, instead of being correlated with tooth deflection, is correlated with a parameter, $\Psi$, that combines tooth deflection (from fully meshed considerations) with distortion at the tooth roots due to tooth bending at seating or unseating. This parameter, defined in more detail in Subsection 2.1, is

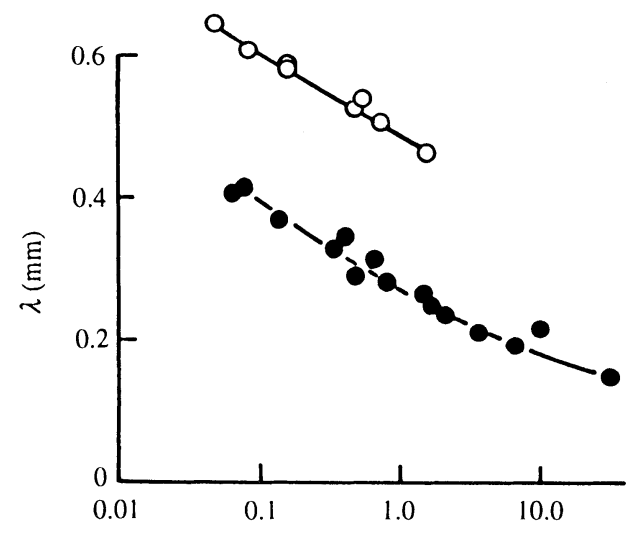

(a)

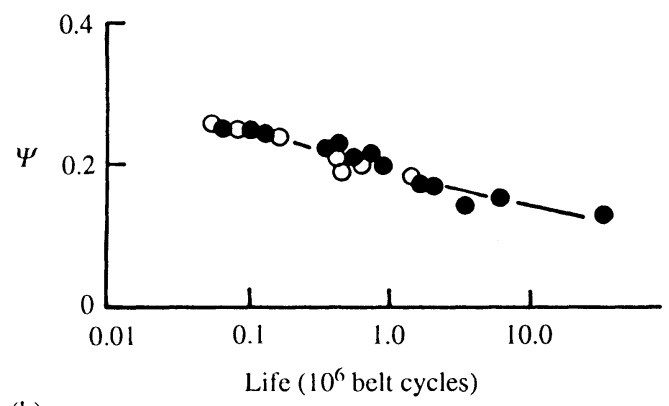

(b)

Fig. 1 Dependence of belt life (failure by tooth root cracking) on (a) tooth deflection and (b) an effective strain parameter, for driver entry $(0)$ and driven exit $(\bullet)$ failures. (From reference [4]) plotted against the life in Fig. 1b. The driven exit and driver entry lives are the same function of $\Psi$.

In this paper, the life investigations are continued, with a differently profiled curvilinear toothed belt, firstly, to check the generality of the conclusion that the life depends on $\Psi$ and, secondly, to extend the testing to conditions that cause failure due to tooth root distortions at driver exit and driven entry.

Although $\Psi$ is found to be more fundamental than $\lambda$ in determining the belt life, it is also much more computationally intensive to calculate its value. Simulations beyond the conditions of the experiments reported here demonstrate (Section 4) a one-to-one relation between $\lambda$ and $\Psi$ at each of the four conditions of the driven and driver entry and exit, when the belt tensions and pulley size (number of teeth) are changed, reinforcing similar conclusions from a previous demonstration [4]. Thus the understanding of failure obtained by introducing $\Psi$ also gives confidence that the more straightforward $\lambda$ may continue to be used in practical life laws, such as equation (1), for the prediction of life in more complicated layouts than torque transmission between two equally sized pulleys. The second purpose of this paper, after presenting the extended life testing results, is to introduce a computer-based design guide that uses experimentally established life laws to predict the effects of changed belt loadings and layouts, as well as of changed belt widths and pitch differences, on the life of typical automotive camshaft drive arrangements.

\section{THEORY}

\subsection{Belt tooth loading and failure measures}

The theory of fully meshed tooth loading, from which estimates of tooth deflection at the driven and driver entry and exit can be obtained, is well known [6-10] but is briefly summarized here for completeness. Figure 2 a shows belt pitches meshed with a pulley. Ignoring the pitches in partial mesh, the pitches are labelled 1 to $N$, from the tight side where the cord tension is $T_{\mathrm{t}}$ to the slack side where it is $T_{\mathrm{s}}$. Figures $2 \mathrm{~b}$ and $\mathrm{c}$ show the details of a general pitch $i$. Circumferential force equilibrium (Fig. 2b) relates tension changes in the cord to the tooth load, $Q$, and land frictional force, $F$ :

$$
T_{i}^{\prime}=T_{i}-Q_{i}, \quad T_{i+1}=T_{i}^{\prime}-F_{i}
$$

Compatibility of meshing (Fig. 2c) relates the tooth deflections, $\lambda$, to the pitch difference between the pulley and stretched belt:

$$
\lambda_{i+1}=\lambda_{i}+\left(P_{\mathrm{p}}-P_{\mathrm{b}}\right)-\left(\mathrm{d} P_{\mathrm{b}}\right)_{i}
$$

Here the pitch stretch $\mathrm{d} P_{\mathrm{b}}$ is supposed to be related to tension, $T$, and $\lambda$ to $Q$, by the linear belt stiffness, $K_{\mathrm{b}}$, and tooth stiffness, $K_{\mathrm{t}}$, respectively: 


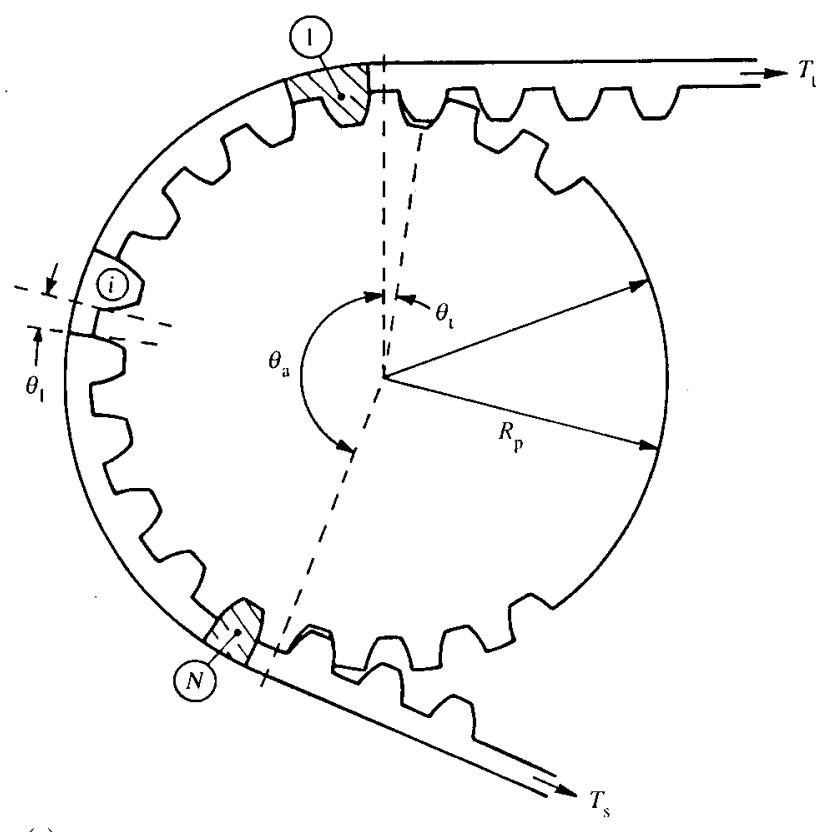

(a)

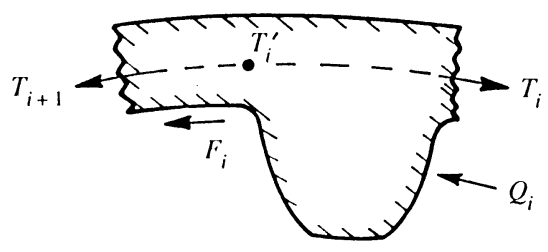

(b)

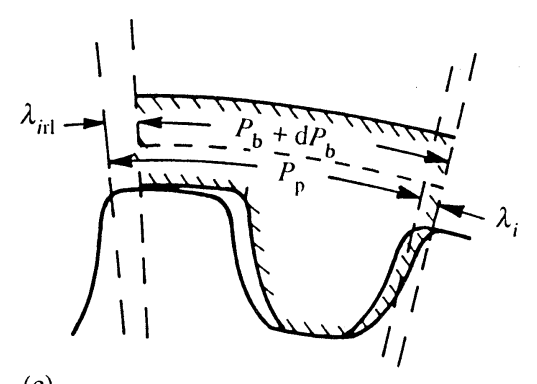

(c)

Fig. 2 (a) An overview and (b), (c) details of a fully meshed timing belt on a pulley

$$
T=K_{\mathrm{b}} \mathrm{d} P_{\mathrm{b}}, \quad Q=K_{\mathrm{t}} \lambda
$$

The land frictional force, $F_{i}$, is obtained from the capstan formula, assuming sliding on the land:

$$
F_{i}=T_{i}^{\prime}\left(1-\mathrm{e}^{-\delta \mu \theta_{1}}\right)
$$

where $\theta_{1}$ is the angular extent of the land and $\delta= \pm 1$, depending on the direction of sliding. Furthermore the stretch, $\left(\mathrm{d} P_{\mathrm{b}}\right)_{i}$, of a pitch under varying tension force, with $R_{\mathrm{p}}$ as the pulley pitch, is [1]

$$
\left(\mathrm{d} P_{\mathrm{b}}\right)_{i}=\frac{R_{\mathrm{p}} \theta_{1}}{P_{\mathrm{b}} K_{\mathrm{b}}} \frac{T_{i}+T_{i}^{\prime}}{2}+\frac{R_{\mathrm{p}} T_{i}^{\prime}}{P_{\mathrm{b}} K_{\mathrm{b}}} \frac{\delta}{\mu}\left(1-\mathrm{e}^{-\delta \mu \theta_{1}}\right)
$$

The system of equations (2) to (6) enables $T_{i+1}$ and $\lambda_{i+1}$ to be calculated from $T_{i}$ and $\lambda_{i}$. Tooth deflections round the arc of contact are obtained by iteration, by altering the value of $\lambda_{1}$ at the tight side until $T_{N}^{\prime}$ at the final pitch, $N$, is equal to the slack side tension, $T_{\mathrm{s}}$. In most cases there is not an integral number of teeth in contact. A best estimate of the tooth deflection at entry and at exit is obtained by interpolating between the estimates obtained from the full mesh calculations assuming the number of teeth in contact to be the integer below and above the actual fractional value.

The direction of sliding on the pulley land depends on the pitch difference between the belt and pulley and on the belt tension. For synchronous motion to be maintained the velocity difference at the pitch line between the pulley and belt, relative to a reference velocity, $V_{0}$, of the unstretched belt, is [5]

$$
\frac{V_{\mathrm{p}}-V_{\mathrm{b}}}{V_{0}}=\frac{P_{\mathrm{p}}-P_{\mathrm{b}}}{P_{\mathrm{b}}}-\frac{F}{K_{\mathrm{b}} P_{\mathrm{b}}}
$$

If, in Fig. 2a, the pulley is regarded as rotating clockwise (representing a driven pulley) and $V_{\mathrm{p}}$ is greater than $V_{\mathrm{b}}$, it can be determined that the frictional force is oppositely directed to the tooth load. Inspection of equation (5) shows that then $\delta=-1$. Thus, on a driven pulley, if $F / K_{\mathrm{b}}<$ $P_{\mathrm{p}}-P_{\mathrm{b}}, \delta=-1$; if not, $\delta=+1$. The opposite is the case on a driving pulley. It can also be seen that, if $V_{\mathrm{p}}$ is greater than $V_{\mathrm{b}}$, tooth deflection reduces from the driven entry to the driven exit and from the driver exit to the driver entry. Adjusting the relative severity of entry and exit tooth deflections by varying $P_{\mathrm{p}}-P_{\mathrm{b}}$ will be used in the experimental work to study entry- and exit-induced belt failures.

Figure 3 looks in more detail at a partially meshing tooth, in this case at the tight side. In addition to the developing tooth deflection, $\lambda_{1}$, the contact forces, $F$ and $N$, between the pulley groove and belt tooth generate a bending moment, $M$, about the tooth centre. This creates a tensile strain in the belt cover in the neighbourhood of the tooth root $I$, in addition to the strain caused by the deflection, $\lambda$. If the tooth is considered as a simple beam, the bending strain at the root is $M y /(E I)$, where $y$ is half the tooth width, $t_{\mathrm{w}}$. If $I$ is taken as $w t_{\mathrm{w}}^{3} / 12$ and $E$ as $K \mathrm{t} / w$, where $w$ is the belt width, an expression for the bending strain is approximately $6 M /\left(K_{\mathrm{t}} t_{\mathrm{w}}^{2}\right)$. A measure of the strain due to the deflection, $\lambda_{1}$, is $\lambda_{1} / t_{\mathrm{d}}$, where $t_{\mathrm{d}}$ is the tooth depth (typically half the tooth width). The parameter $\Psi$ developed in reference [4] for the effective tooth root strain during tight side partial meshing is a simple addition of the two strains:

$$
\Psi=\frac{\lambda_{1}}{t_{\mathrm{d}}}+\frac{6 M}{K_{\mathrm{t}} t_{\mathrm{w}}^{2}}
$$




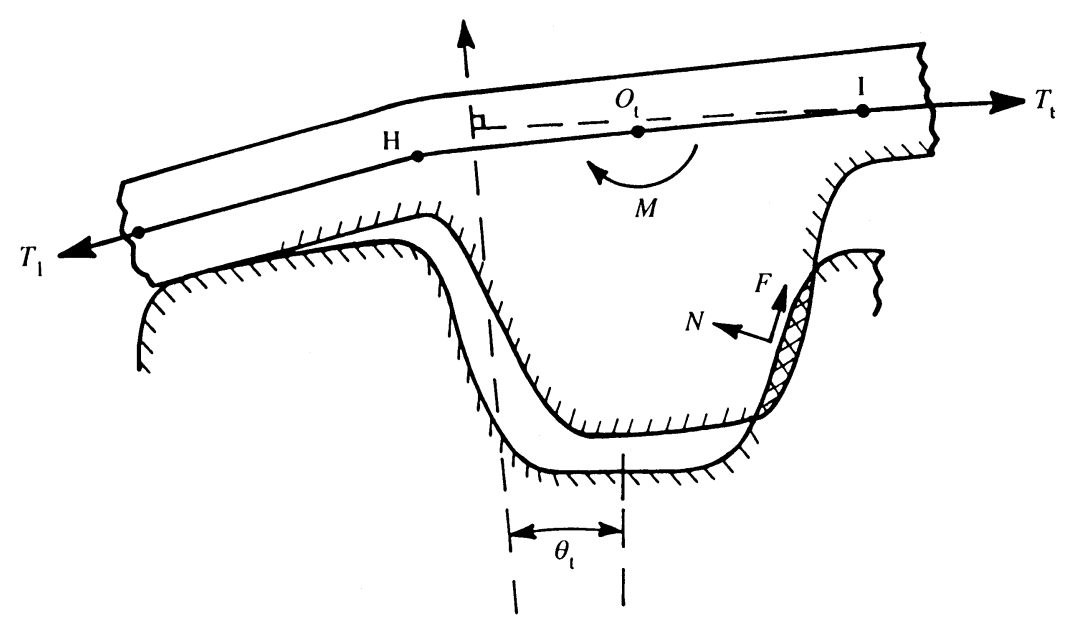

Fig. 3 A detail of a partially meshed tooth (at tight side entry)

A similar expression, with $\lambda_{N}$ instead of $\lambda_{1}$, gives the effective root strain during slack side partial meshing. The calculation of $M$ from the belt tooth circumferential, radial and moment equilibrium during partial meshing, to determine the maximum value of $\Psi$, has been described fully in reference [4] and is used identically in this paper to assess its relationship to belt life.

\subsection{Computer-based design guide development}

The design guide seeks to estimate the life of a belt making a circuit round any number of pulleys (up to 19 in all) in fluctuating torque conditions. It has only been developed to deal with single-sided toothed belts. Figure 4 shows a general layout of $N_{\mathrm{p}}$ pulleys. That labelled number 1, at the origin of coordinates, is the driver (crank) pulley, acting on the belt with a torque, $T Q_{1}$. In this example, pulley 2 happens to be a tensioner pulley; the torque, $T Q_{2}$, that it exerts on the belt will frequently be zero, but this may not be the case. There are then imagined to be pulleys between pulley 2 and pulley $i-1$ which are not shown in the figure. Pulleys $i-1, i$ and $i+1$ are next to each other; then pulley $N_{\mathrm{p}}$ is the final pulley in the run. In this example, pulleys $i-1$ and $i$ are toothed, and that determines which side of the belt contacts them. Pulley $i+1$ happens to be not toothed; it runs on the back of the belt. The first part of the design guide, after entry of information defining the proposed belt (the pitch, land length, tooth and tension member stiffness per unit width, width, friction and life data) accepts information on the pulley centre coordinates, the number of teeth (and hence, with the pitch, the diameter) of toothed pulleys and the diameter of back contact pulleys, to calculate the angle of wrap on all the pulleys and the required total length of the belt. (The pitch difference of the toothed pulleys from the belt pitch is also entered at this stage, needed later in tooth deflection calculations.)

The angle of wrap calculation can be explained by referring to the pulleys $i-1$ to $i+1$. As previously

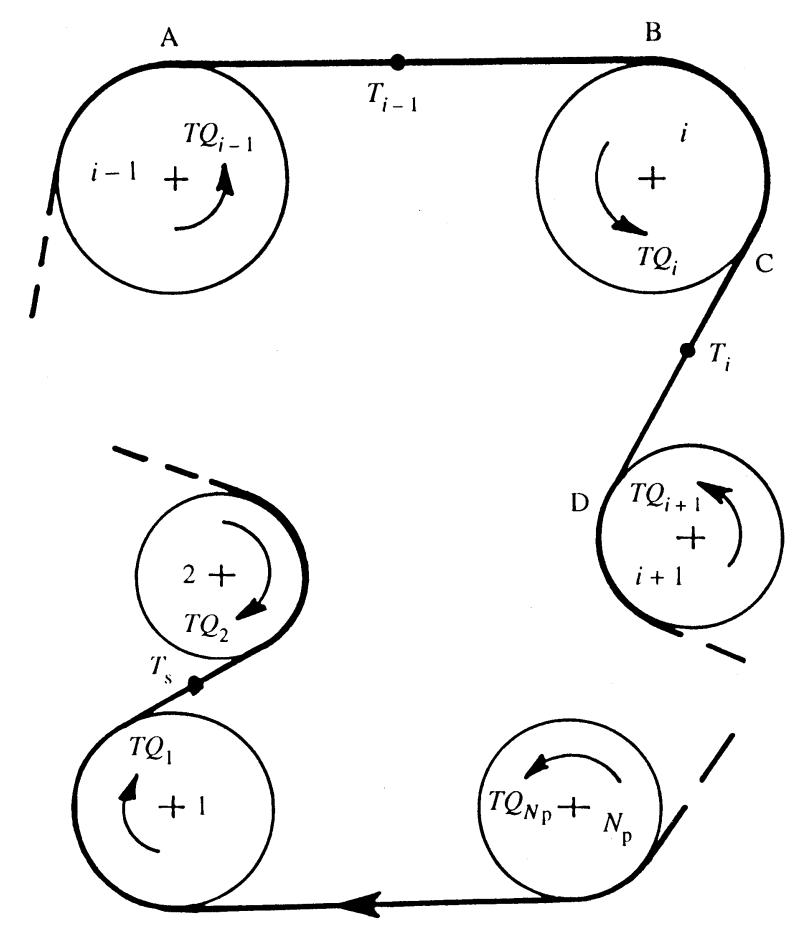

Fig. 4 A general pulley and belt layout

stated, pulleys $i-1$ and $i$ are both toothed. The path of the belt strand $\mathrm{AB}$ is an outside common tangent to the pulleys, contacting them at $\mathrm{A}$ and $\mathrm{B}$. The coordinates of $\mathrm{A}$ and $\mathrm{B}$ are found from the pulley centres and their radii. Pulley $i+1$ is not toothed, so the common tangent belt path $\mathrm{CD}$ is one which crosses the line of centres between pulleys $i$ and $i+1$; the positions of $\mathrm{C}$ and $\mathrm{D}$ are likewise found from the centres of the two pulleys $i$ and $i+1$ and their radii. If two adjacent pulleys are both toothless, the belt path between them is an inside common tangent. On each pulley in turn, the start and end of contact are found from knowledge of what tangent path is expected to the adjacent pulleys and the positions of the centres and 
diameters of the pulleys. The arcs of contact (e.g. BC on pulley $i$ ) are then calculated.

The software that has been written to calculate the arcs of contact also carries out a number of checks: that the pulleys do not clash, that belt strands do not touch or cross over one another, that a pulley does not contact a belt strand other than the two to adjacent pulleys, and that the layout is possible in the sense that a belt can contact all the pulleys in the order intended. The last is a check that all the arcs of contact are positive. The software also warns whether any toothed pulley has only a small number (less than five) teeth in mesh and whether any of the back contact pulleys are of a smaller diameter than the smallest toothed pulley. It also warns whether the belt width is wider than the diameter of the smallest pulley. Belt manufacturers' catalogues advise that such circumstances be avoided, but their occurrence does not prevent the running of the program.

After the layout has been established, belt loadings are entered and the life calculation is carried out. In steady torque transmission conditions (no torque fluctuations), the procedure is straightforward. A slack side tension, $T_{\mathrm{s}}$, between pulleys 1 and 2 is assumed. All the other strand tensions are calculated from this and knowledge of the pulley torques, $T Q$. In general, referring to Fig. 4,

$$
T_{i}=T_{i-1}+\frac{T Q_{i}}{R_{i}}
$$

where $R_{i}$ is the radius of pulley $i$. With $i=2, T_{2}$ is calculated from $T_{\mathrm{s}}$, with $i=3, T_{3}$ from $T_{2}$, and so on round the circuit. The entry tooth deflection $\lambda_{i, 1}$ and exit tooth deflection $\lambda_{i, N}$ are then calculated for all the toothed pulleys $i=1$ to $k$, from the full mesh theory described in Subsection 2.1. Finally the four lives for driven and driver entry and exit failures are calculated, assuming a Palmgren-Miner law commonly used for variable loading fatigue studies [11]. The shortest life is assumed to determine failure. The program records which of the four lives is the shortest and indicates on which pulley the main contribution to failure occurs.

It is supposed, in applying the Palmgren-Miner law, that the driven entry life $L_{\mathrm{dn} \text {-en }}$ and driven exit life $L_{\mathrm{dn} \text {-ex }}$ are found from

$$
\frac{1}{L_{\mathrm{dn}-\mathrm{en}}}=\sum_{i=2}^{k} \frac{1}{L_{i, \mathrm{dn}-\mathrm{en}}}, \quad \frac{1}{L_{\mathrm{dn}-\mathrm{ex}}}=\sum_{i=2}^{k} \frac{1}{L_{i, \mathrm{dn}-\mathrm{ex}}}
$$

where $L_{i, \mathrm{dn} \text {-en }}$ and $L_{i, \mathrm{dn} \text {-ex }}$ are the lives that would be obtained if the belt ran on driven pulley $i$ alone. They are obtained from the calculated $\lambda_{i, 1}$ and $\lambda_{i, N}$ and life law relations such as in Fig. 1a (and as later are found in Fig. 6). In the case of steady torque transmission, there is only one driver pulley, on the crank shaft. $L_{1, \mathrm{dr} \text {-en }}$ and $L_{1, \mathrm{dr} \text {-ex }}$ are found directly from $\lambda_{1,1}$ and $\lambda_{1, N}$ and the appropriate driver failure life law.
The situation is more complicated if fluctuating torques occur. Firstly, the strand tensions vary with time. Exact calculation of tension needs torque fluctuation amplitudes and phases on the different pulleys to be known. Although measurements are made in practice of the fluctuation amplitudes, knowledge of the phase differences is not usually available. Secondly, large-amplitude fluctuations can momentarily cause normally driven pulleys to become drivers and the crank pulley to be driven. Thirdly, inertia effects may affect tensions. The present theory ignores inertia; it supposes that a fluctuating torque is simply a distribution of steady torques, causing a distribution of tight and slack side tensions on a pulley and hence a distribution of entry and exit tooth deflections.

The calculation of strand tensions is approximate. Firstly the average torque is calculated on every pulley and the average strand tensions are obtained from equation (9), assuming that $T_{\mathrm{s}}$ remains constant. Then, representing the distribution of torque on pulley $i$ by $m_{i}$ values each of which occur with equal probability, equation (9) is applied again, $m_{i}$ times, to calculate a distribution of tight side tensions for each pulley, assuming the slack side tension to remain constant at its mean value. The corresponding distribution of entry and exit tooth deflections is then calculated as before. The assumption that the slack side tension remains constant as the torque varies is one of convenience. It prevents the possibility that a negative belt tension is predicted by the program, and tooth deflections are much more dependent on the tight and slack side tension difference round a pulley than on the sum of these tensions. For every tight and slack side combination, the program checks that the traction coefficient (tension difference divided by tension sum) is not so large that it is likely to cause the belt teeth to jump out of the pulley grooves. A maximum traction coefficient of 0.7 is set in the program, according to common design practice. If that value is exceeded for any choice of $T_{\mathrm{s}}$, a larger $T_{\mathrm{s}}$ must be chosen.

The distribution of tooth deflections is then used to create an extended form of equation (10), as follows:

$$
\begin{aligned}
& \frac{1}{L_{\mathrm{dn}-\mathrm{en}}}=\sum_{i=1}^{k} \frac{1}{m_{i}} \sum_{j=1}^{\alpha m_{i}} \frac{1}{L_{(i, j) \mathrm{dn}-\mathrm{en}}} \\
& \frac{1}{L_{\mathrm{dn}-\mathrm{ex}}}=\sum_{i=1}^{k} \frac{1}{m_{i}} \sum_{j=1}^{\alpha m_{i}} \frac{1}{L_{(i, j) \mathrm{dn}-\mathrm{ex}}} \\
& \frac{1}{L_{\mathrm{dr}-\mathrm{en}}}=\sum_{i=1}^{k} \frac{1}{m_{i}} \sum_{j=1}^{(1-\alpha) m_{i}} \frac{1}{L_{(i, j) \mathrm{dr}-\mathrm{en}}} \\
& \frac{1}{L_{\mathrm{dr}-\mathrm{ex}}}=\sum_{i=1}^{k} \frac{1}{m_{i}} \sum_{j=1}^{(1-\alpha) m_{i}} \frac{1}{L_{(i, j) \mathrm{dr}-\mathrm{ex}}}
\end{aligned}
$$

Here a fraction, $\alpha$, of the $m_{i}$ torque values in the 
distribution result in a pulley acting as a driven pulley, and $(1-\alpha) m_{i}$ are driver conditions. The inner summation for driven failures is carried out on the subset of driven torque conditions, and on the subset of driver torque conditions for driver failures.

The design guide is applied to an automotive camshaft drive layout, with experimental life data linking lives and tooth deflections at all four failure sites, in Subsection 4.2.

\section{EXPERIMENTATION}

The life-testing dynamometer has been described before [ $\mathbf{1}$, 3]. Briefly, it is a back-to-back power recirculating rig in which a timing belt under test transmits torque between two parallel shafts rotating at equal speed, usually $3000 \mathrm{r} / \mathrm{min}$. One shaft which contains a torque transducer is supported by rolling bearings in blocks fixed to the main frame of the dynamometer; it is to this that an $11 \mathrm{~kW}$ motor supplies the system losses. The other shaft is supported on a subframe that slides on linear bearings over the main frame; belt tension is generated by jacking bolts between the subframe and mainframe and is measured by a load cell on which the bolts press. The test belt end of each of the two shafts protrudes into an environmental chamber that enables temperature to be controlled up to $150{ }^{\circ} \mathrm{C}$.

Figure 5 shows various belt layouts that can be achieved in the chamber. Figure $5 \mathrm{a}$ is the basic layout, torque transmission between two 19-tooth pulleys fixed to the two shafts. Figure $5 \mathrm{~b}$ is a second layout in which the angle of wrap on the 19-tooth pulleys is altered by a 38-tooth pulley acting as an idler (nominally zero torque on its support shaft). Angles of wrap can further be altered by back idler flat pulleys (Figs 5c and d). Tests with the three-pulley layout (Fig. 5b) confirmed earlier studies [1] that this layout gave the same failure modes as with the two-pulley layout (Fig. 5a). The life tests reported here have been carried out with the layouts in Figs 5a, c and d, as listed in Table 1, where $\theta_{\mathrm{a}}$ refers to the angle of wrap. The tests have all used 116-tooth belts $19.75 \mathrm{~mm}$ wide and nominally of $9.519 \mathrm{~mm}$ pitch supplied from one batch and intended in

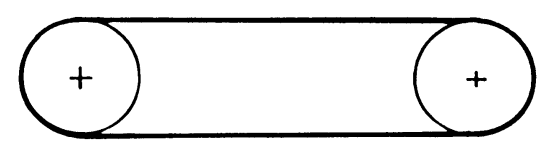

(a)
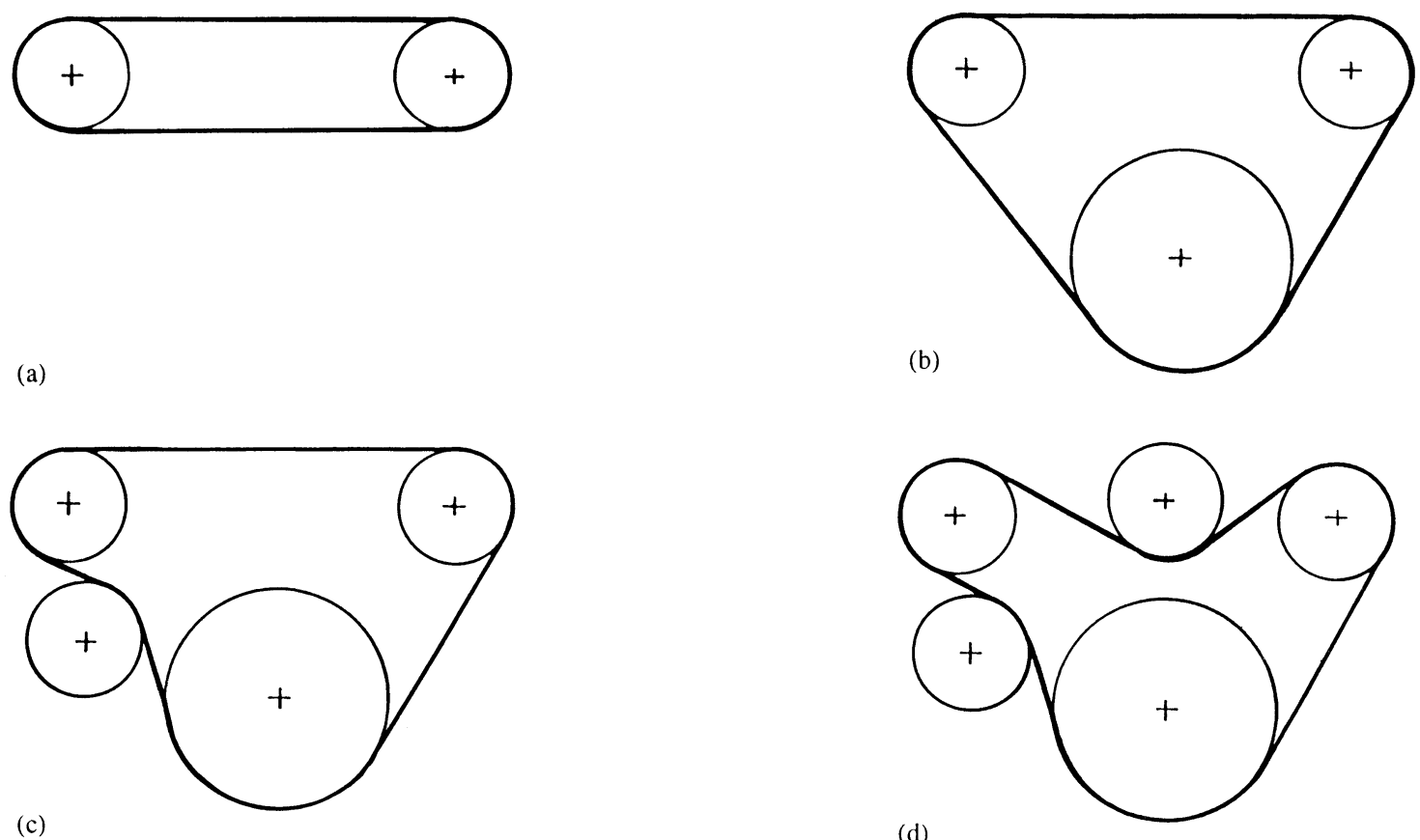

(d)

Fig. 5 Four belt layouts used for life testing

Table 1 Test series and conditions

\begin{tabular}{|c|c|c|c|c|c|c|c|}
\hline \multirow{2}{*}{$\begin{array}{c}\text { Test } \\
\text { series }\end{array}$} & \multirow{2}{*}{$\begin{array}{c}\text { Temperature } \\
\left({ }^{\circ} \mathrm{C}\right)\end{array}$} & \multirow[b]{2}{*}{ Layout } & \multicolumn{2}{|c|}{ Driven pulley } & \multicolumn{2}{|c|}{ Driver pulley } & \multirow{2}{*}{$\begin{array}{l}\text { Planned } \\
\text { failure } \\
\text { source }\end{array}$} \\
\hline & & & $\theta_{\mathrm{a}}(\mathrm{deg})$ & $P_{\mathrm{p}}-P_{\mathrm{b}}(\mathrm{mm})$ & $\theta_{\mathrm{a}}(\mathrm{deg})$ & $P_{\mathrm{p}}-P_{\mathrm{b}}(\mathrm{mm})$ & \\
\hline 1 & $100-140$ & Fig. 5a & 180 & 0.003 & 180 & 0.003 & Driven exit \\
\hline 2 & 120 & Fig. 5c & 180 & 0.0483 & 120 & 0.002 & Driver entry \\
\hline 3 & 120 & Fig. $5 \mathrm{c}$ & 180 & 0.0483 & 120 & 0.0605 & Driver exit \\
\hline 4 & 120 & Fig. $5 d$ & $120^{*}$ & $0.0605 \dagger$ & 180 & 0.002 & Driven entry \\
\hline
\end{tabular}

* Some tests were also carried out with $\theta_{\mathrm{a}}=130^{\circ}$.

$\dagger$ Some tests were also carried out with $0.0483 \mathrm{~mm}$. 
the field for diesel engine use. Different pulleys have been measured and selected for use to give different pitch differences from the belts. In test series 1 (Table 1), it was anticipated from the previous work [1] that driven exit tooth loadings would be life determining; the effect of test temperature on life was investigated, before deciding to concentrate on a test temperature of $120^{\circ} \mathrm{C}$ for the subsequent tests. In series 2, a reduced driver pulley angle of wrap was chosen, with an oversized driven pulley (to reduce driven exit tooth loads), to create the driver entry condition as most severely loaded. In series 3 , an oversized driver pulley was used, to shift the most severe tooth loading to the driver exit. In series 4 , the driven pulley was oversize, to create the most severe tooth loading at driven entry. As will be seen in Section 4, driven entry failures proved difficult to realize; an extremely oversize pulley (pitch difference, $0.0605 \mathrm{~mm}$ ) had to be used to reduce driven exit tooth loads sufficiently relative to driven entry loads; an initial attempt to create driven entry failures by choosing a pulley of $0.0483 \mathrm{~mm}$ pitch difference resulted in driven exit failures.

In each series, tests were carried out at constant torque, in the range $15-30 \mathrm{Nm}$, and at constant total tension, between 1 and $2 \mathrm{kN}$. At the start of a test, the belt tension showed a tendency to relax with time [12]. Belts were retensioned to compensate for this. Tests were continued until synchronous transmission was lost. The number of shaft revolutions to loss of synchronous motion was recorded and converted to the number of belt revolutions by multiplying the shaft revolutions by the ratio $19 / 116$ (the ratio of the number of pulley teeth to the number of belt teeth). The latter is reported as the belt life.

The tooth stiffness, $K_{\mathrm{t}}$, the cord extension stiffness, $K_{\mathrm{b}}$, and the sliding friction coefficient, $\mu$, are required for the full mesh tooth deflection calculation. Values appropriate for the belt type used here are $415 \mathrm{~N} / \mathrm{mm}, 47400 \mathrm{~N} / \mathrm{mm}$ and 0.2 respectively, determined as described previously [3]. In addition, $K_{\mathrm{p}}$ is needed for the estimate of bending strain at seating and unseating. This was assumed to equal $K_{\mathrm{t}} /$ tooth depth as before [4]; the tooth depth was $3.4 \mathrm{~mm}$. The tooth width at the cord line was near to $6 \mathrm{~mm}$.

\section{RESULTS}

\subsection{Life tests and correlations}

Figure 6 summarizes the life-testing observations. The fully meshed loading theory has been used to convert the test torque and tension data to both the tooth load and the tooth deflection at driven or driver entry or exit, as appropriate for the failure condition. It can be seen that different laws relate tooth deflection/load to life, depending on the failure site. Table 2 lists the coefficients $A^{*}$ and $B^{*}$ of equation (1b) appropriate for lives at $120^{\circ} \mathrm{C} . A$ and $B$ [equation (1a)] can be found by dividing $A^{*}$ and $B^{*}$ by $K_{\mathrm{t}}$ $(415 \mathrm{~N} / \mathrm{mm})$. The slopes of the life curves fall into two

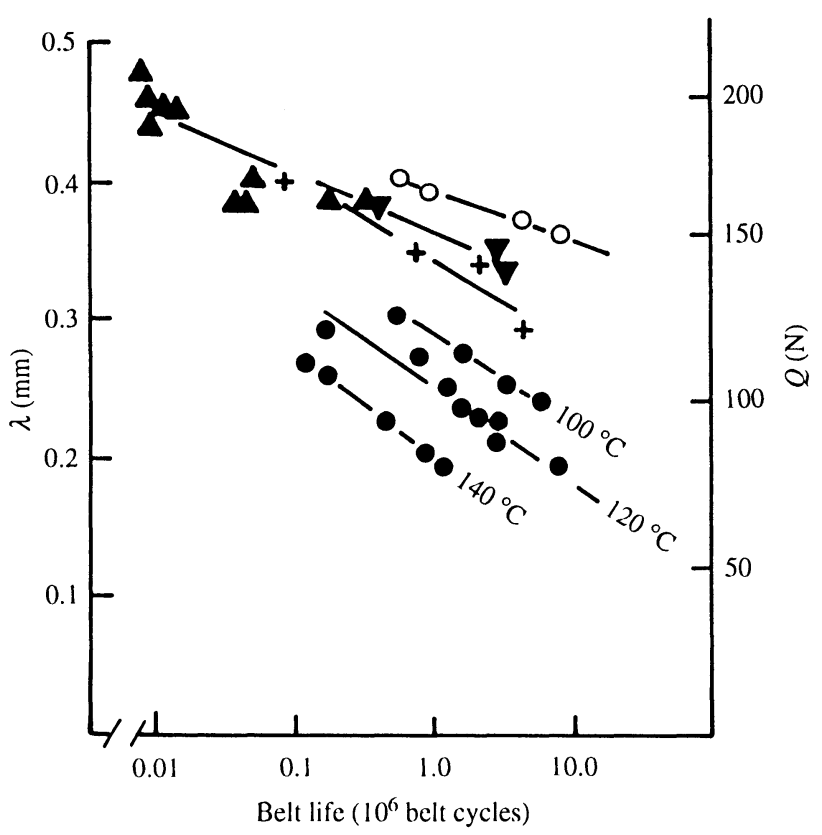

Fig. 6 Tooth deflection-belt life relationships found for driven exit $(\bullet)$, driven entry $(\circ)$, driver entry $(+)$ and driver exit $(\boldsymbol{\nabla}, \boldsymbol{\Delta})$ failures; all data for testing were at $120^{\circ}$ except where indicated; all failures were by tooth root cracking except $(\boldsymbol{\Delta})$ which were by fabric separation

Table 2 Belt life law coefficients $A^{*}$ and $B^{*}$ at $120^{\circ} \mathrm{C}$ [equation (1)]

\begin{tabular}{ccccc}
\hline & \multicolumn{4}{c}{ Value at the following } \\
\cline { 2 - 5 } Failure mode & Driven exit & Driven entry & Driver exit & Driver entry \\
\hline$A^{*}(\mathrm{~N})$ & 104 & 160 & 150 & 140 \\
$B^{*}(\mathrm{~N})$ & 29.0 & 14.5 & 18.3 & 26.0 \\
\hline
\end{tabular}

groups; in tight side conditions (driven exit and driver entry) the slopes are almost twice those in slack side conditions. The driven exit life law is also significantly displaced to lower lives relative to the three other laws.

Figure 6 also shows how the driven exit lives depended on the test ambient temperature. All observed failures were by tooth root cracking except the short life driver exit failures; in this condition, the belt cover fabric separated from the belt cord. The single life law in Table 2 for the driver exit is a fit of both tooth root cracking and fabric separation failures to a single line.

It might be asked how a belt failure can be assigned to one of the four partial meshing conditions. All the failures described as driven showed tooth root cracking on the tooth flanks carrying load on the driven pulley; driver failures showed cracking on the opposite flank. To distinguish between an entry and exit failure, it was first assumed that the failure would occur at the most heavily loaded (or strained) contact. It was then checked whether as good a correlation between life and load (or strain) could be 
achieved by assigning the failure to the less heavily loaded (strained) condition; if it could be, the failure was reassigned to that condition. In the conditions of these tests, reassignment only occurred in trying to achieve driven entry failure.

It might also be asked why it is assumed that a failure is due to loading only in one partial meshing condition. Failure could accumulate from contributions to loading at several different sites. The only answer to that is that test conditions were chosen to make one failure condition dominant and that, with the possible exception of the driven entry data, the assumption leads to a unique relation between effective strain and life, as considered next.

The partial meshing theory outlined in Subsection 2.1 was used to estimate the effective strain, $\Psi$ [equation (8)], for all the $120^{\circ} \mathrm{C}$ data in Fig. 6. Figure 7 shows that the driven exit, driver entry and driver exit life data collapse on to a single line when plotted as dependence of life on $\Psi$. Only the driven entry data do not conform.

Partial meshing calculations were also carried out to check the extent to which a one-to-one relation exists between $\Psi$ and $\lambda$ in each of the four partial meshing states, under varying conditions of belt tension, pitch difference and pulley size, but keeping the belt tooth profile and material properties constant. In an initial set of calculations in driven exit conditions, it was found that the relation between $\Psi$ and $\lambda$ was unaffected by the variables belt tension, pitch difference and angle of wrap on the pulley. Changing these (the ranges of change were kept to sensible practical levels) just caused different exit tooth deflections. However, changing the pulley diameter (the number of teeth) did influence the relation. Figure 8a shows how the relation between $\Psi$ and $\lambda$ changed with pulley size, from 15 to 38 teeth. The dashed line, in this and the other parts of Fig. 8, is the minimum expected value of $\Psi$, taking $M=0$ in equation (8). A deduction from Fig. $8 \mathrm{a}$ is that, if there is a single relation between $\Psi$ and belt life, this will show up as different relations between $\lambda$ and life for different pulley sizes; for a larger pulley a larger tooth deflection is allowed for a given life, the larger the pulley. However, in changing from a 19- to a 38-tooth pulley, for example, as is the common range of automotive crank and

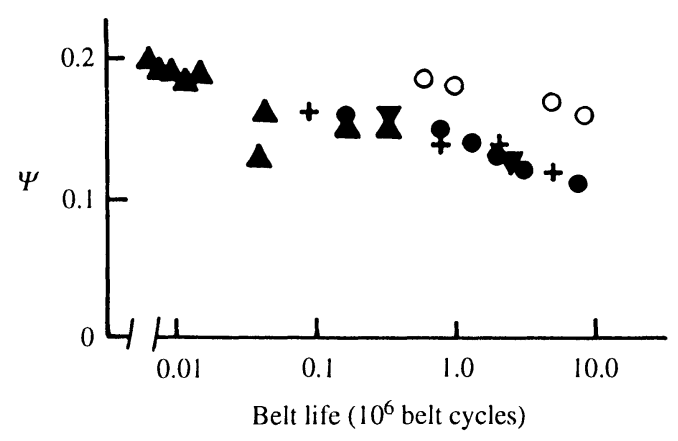

Fig. 7 Dependence of the life on the effective strain; data transformed from Fig. 6
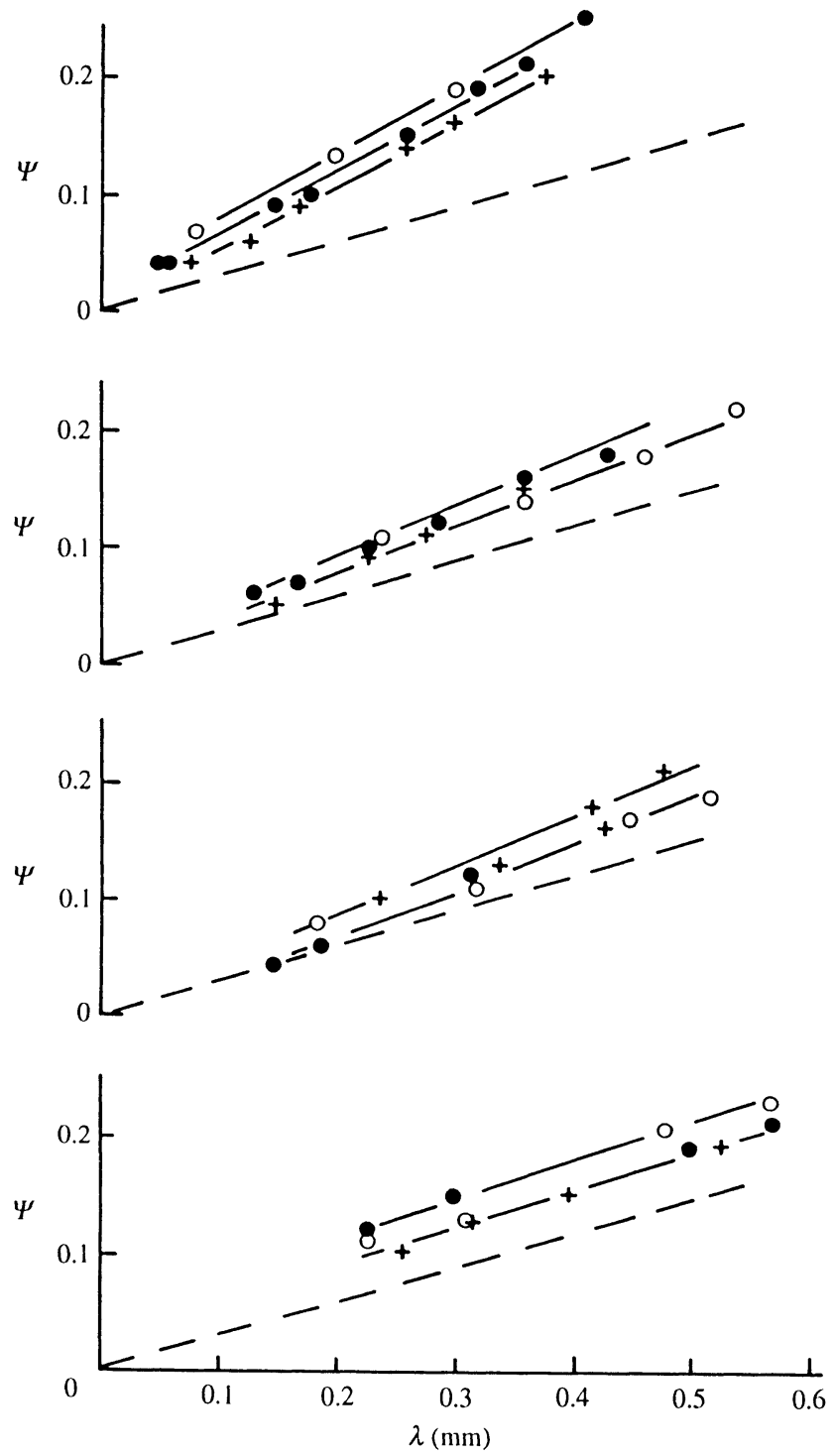

Fig. 8 One-to-one relations between $\Psi$ and $\lambda$ calculated in (a) driven exit, (b) driver entry, (c) driver exit and (d) driven entry conditions, for pulleys with $15(\mathrm{O}), 19(\bullet)$ and 38 $(+)$ teeth

cam pulley sizes, the effect is so small that it would hardly be observable above the scatter in life data in Fig. 6. The possible influence of pulley size on $\lambda$-life laws will be ignored here.

Figures $8 \mathrm{~b}$ to $\mathrm{d}$ show the different $\Psi-\lambda$ relations calculated at the other partial meshing conditions. They all show a scatter similar to that in Fig. 8a, but with no clear trend with pulley size. In the following subsection the conclusion that tooth root cracking is uniquely related to an effective strain measure that can be transformed to equivalent tooth deflections or loadings at driver and driven entry and exit is used to predict the effects of layout and loading on life in conditions approaching automotive practice, in the manner described in Subsection 2.2. 


\subsection{Design guide predictions and sensitivity analyses}

The software described in Subsection 2.2 has been used, with life data from Table 2 and the measured belt stiffness and friction data, to study the sensitivity of belt life to changes in layout, belt width and pitch, pulley diameter (number of teeth), tension setting and dynamic torque level. Figure $9 \mathrm{a}$ shows the representative twin-cam layout, with a water pump and tensioner pulley, that has been used for the study. Table 3 records the base conditions used in the calculations. The torque ranges on the cam and crank pulleys represent mean values of 7.5 and $9.4 \mathrm{Nm}$, and amplitudes of oscillation of 10 and $15 \mathrm{Nm}$ respectively.
Table 3 Base conditions for design guide sensitivity analysis, layout as in Fig. 9a

\begin{tabular}{ll}
\hline Belt data & \\
Belt width $(\mathrm{mm})$ & 20 \\
$P_{\mathrm{p}}-P_{\mathrm{b}}(\mathrm{mm})$ & 0.012 \\
Pulley size & 20 \\
Crank $N$ (teeth) & 40 \\
Cam $N$ (teeth) & 21 \\
Water pump $N$ (teeth) & 38 \\
Tensioner $R$ (mm) & 200 \\
Tension, $T_{\mathrm{s}}$, at crank $(\mathrm{N})$ & \\
Torque $(\mathrm{N}$ m) & Sinusoidal, from -2.5 to +17.5 (on each \\
Cam & camshaft) \\
& Sinusoidal, from -5.6 to +24.4 \\
Crank & Steady, 2 \\
Water pump &
\end{tabular}

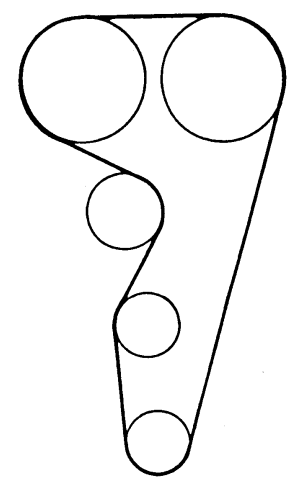

(a)
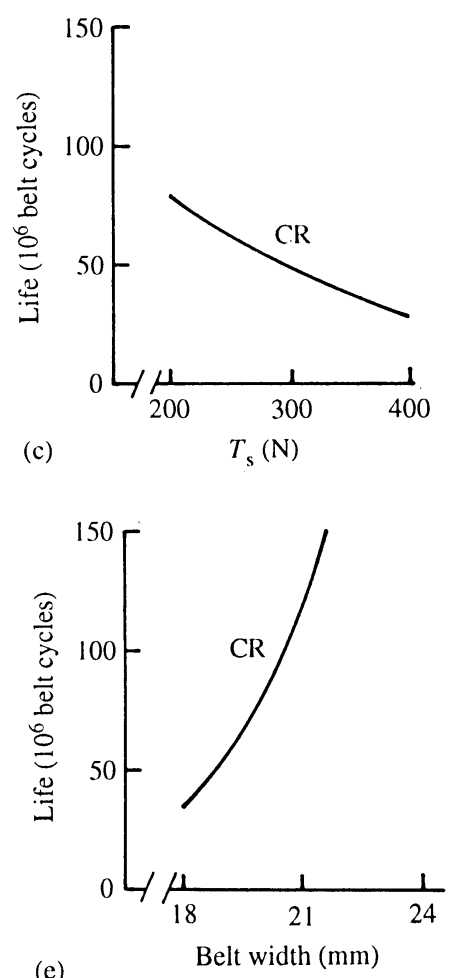

(e)

Fig. 9 (a) A typical timing belt layout, and (b) to (f) the predicted sensitivit

y of the life to changes around the conditions of Table 3. Failures are predicted as due to belt loading on the crank pulley (CR) or the water pump (WP)

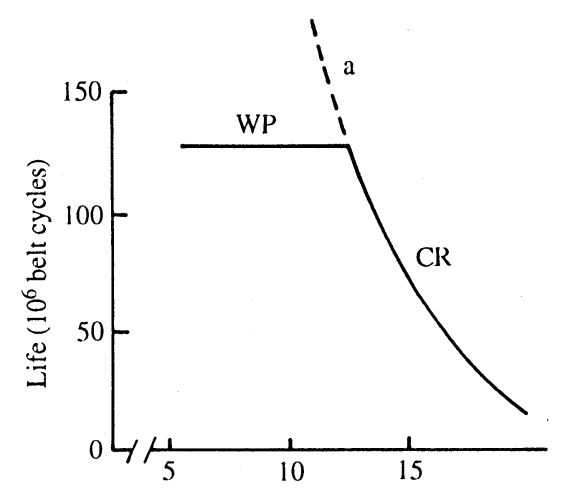

(b)
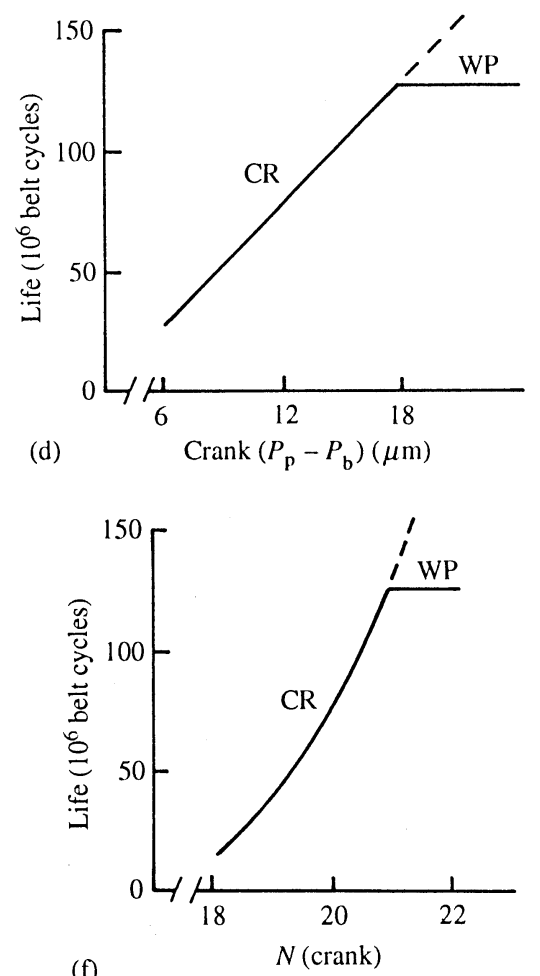

(f) 
The chosen slack side tension at the crank is the smallest value at which synchronous motion is attained on the crank pulley (belt jumping out of the pulley grooves is predicted for smaller values). For these conditions, which are not unreasonable for a medium-size automotive passenger car (but which have been made up, to avoid commercial sensitivity issues), a life of 80 million belt revolutions is predicted, with failure caused by conditions at driver (crank) entry. For a 130-tooth belt (as is the case in this example) and a 20 -tooth crank pulley, this is equivalent to 520 million crankshaft (or engine) revolutions, approximately equivalent to 170000 road miles if the engine were to be driven at only $3000 \mathrm{r} / \mathrm{min}$, yielding $60 \mathrm{miles} /$ hour. Of course, engine field test conditions and duty cycles are more complicated than those created in the dynamometer tests on which this life prediction is based. In practice, lower lives are likely. The main interest of Fig. 9 is to show how small changes from the base condition can easily cause at least a threefold reduction in estimated life.

Figures $9 \mathrm{~b}$ to $\mathrm{f}$ show how predicted life varies with change of conditions from those in Table 3, varying only one quantity at a time. Figure $9 b$ shows the effect of crank torque oscillation amplitude. Life is strongly dependent on this, indicating the value of crankshaft vibration dampers. In this example, if the amplitude is reduced below $12.5 \mathrm{Nm}$, the failure mode is predicted to become dependent on the water pump tooth loading. The dashed line $\mathrm{a}$ is obtained by moving the tensioner pulley to increase the angle of wrap on the water pump. Figure 9c shows the reduced life on increasing the slack side tension more than is necessary to avoid belt jumping. Figure $9 d$ shows the increased life with the increased pitch difference on the crank pulley (obtained, for example, by choosing the crank pulley appropriately oversized), up to the limit at which failures occur first owing to loading on the water pump. Figures $9 \mathrm{e}$ and $\mathrm{f}$ show the extreme sensitivity of life to the belt width and crank pulley size (number of teeth), respectively. In estimating the effect of the belt width on the life, $K_{\mathrm{b}}$ and $K_{\mathrm{t}}$ are assumed to grow in proportion to belt width; the life laws in terms of tooth deflection [equation (1a)] are assumed to be independent of width.

The predictions in Fig. 9 are in accord with expectations from experience, although it must be pointed out that predicted lives of around $10^{8}$ belt revolutions are an order of magnitude larger than the longest lives measured in this work (Fig. 6). There must be increasing uncertainty in the accuracy of the life laws the further the predicted lives are from the experimentally studied range.

\section{DISCUSSION}

This paper makes two contributions to the study of the timing belt life: firstly, improved understanding of tooth root cracking; secondly, the creation of software to help to assess the influences of the layout and size design changes on the life. The latter has been driven by automotive pressures to reduce under-bonnet package sizes, but the software should be useful to any timing belt user, provided that the relevant life laws are available.

The experimental studies of failures have shown, with one exception, that the life can be related to a measure of strain, $\Psi$, that is a combination of the strain due to tooth loading, $Q$, and to tooth bending, $M$, in the partial meshing state. Studies by other workers are coming to similar conclusions, albeit with different measures of that strain and views of whether the strain causes failure by direct breakdown of the cover (as is believed here) or by breakdown of the elastomer-cover or cord interface in the vicinity of the tooth root $[13,14]$. The present work puts a value of between 0.1 and 0.2 (Fig. 7) for the size of the strain that causes fatigue failure between $10^{8}$ and $10^{4}$ loading cycles at $120^{\circ} \mathrm{C}$. The influence of temperature, from 100 to $140{ }^{\circ} \mathrm{C}$, on the life has also been studied (Fig. 6). It remains for further work to consider more carefully the materials' engineering aspects of how fatigue failure may be delayed (whether by modifying tooth stiffness by changing the cover characteristics or by considering the adhesion between the cover and the other belt components), and extending the life studies over a wider temperature range, particularly towards room temperature, to observe the intervention of other failure modes such as cover wear. It also remains for further work to investigate the driven entry conditions which do not give the same relation between $\Psi$ and life as the other partial meshing conditions. Preliminary finite element studies suggest that it may be the partial meshing calculation of $M$ (Section 2.2) that is in error in this case.

The design guide that has been developed to predict belt life by combining the experimental tooth deflection life laws with calculations of fully meshed tooth deflection, and supposing that loss of life accumulates in a linear manner as is frequently assumed in variable-amplitude fatigue studies [equation (11)], gives sensible results when applied to a case study (Fig. 9). A core now exists that can be extended to other conditions as life data becomes available, or that could be used to assess what belt improvements would be needed for heavier-duty uses.

\section{CONCLUSION}

Four sets of experimental conditions have been found which cause belts to fail by tooth root cracking due to the conditions at driven exit, or at driver entry, or at driver exit, or at driven entry. The laws relating the belt life to the tooth deflection (calculated by ignoring additional distortions due to bending during partial meshing) are different in all four conditions. If the additional distortions due to bending are allowed for, a single life law is achieved in three cases out of the four. Work is continuing to determine what is different about the fourth driven-entry failure case. With 
the possible exception of this fourth case, it has been shown that, although including the partial meshing distortions is essential to a fundamental understanding of failure, the easier-to-calculate deflections ignoring partial meshing may be reliably used in sensitivity analyses to predict the effects on life of varying the layout and sizing of a belt drive. The results of the research have been embodied in software to guide belt users. Examples of its use are given that show, for a twin-cam layout, a large sensitivity of the life to the belt width, pulley size (number of teeth) and torque oscillations (such as occur owing to crankshaft and camshaft vibration in automotive conditions), and a lower sensitivity to the pitch difference between belt and pulley and to the overall tensioning of the system. These predictions are in general agreement with experience, increasing confidence in the guide.

\section{ACKNOWLEDGEMENTS}

The work was carried out under the main sponsorship of the UK Engineering and Physical Sciences Research Council, with the support of companies including Dayco PTI SpA and DuPont de Nemours International SA. Initial work on the design guide was carried out by Dr I. K. Parker [15]; the authors would also like to thank Mr M. J. Tutt for carrying out some simplification and development of the design guide software.

\section{REFERENCES}

1 Childs, T. H. C., Coutsoucos, A., Dalgarno, K. W., Day, A. J. and Parker, I. K. Life prediction of automotive timing belts. In Proceedings of the International Conference on Motion and Power Transmission, 1991, pp. 376-381 (Japan Society of Mechanical Engineers, Tokyo).

2 Dalgarno, K. W., Day, A. J. and Childs, T. H. C. Finite element analysis of synchronous belt tooth failure. Proc. Instn
Mech. Engrs, Part D, Journal of Automobile Engineering, 1993, 207(D2), 145-153.

3 Dalgarno, K. W., Day, A. J. and Childs, T. H. C. Synchronous belt materials and belt life correlation. Proc. Instn Mech. Engrs, Part D, Journal of Automobile Engineering, 1994, 208(D1), 37-48.

4 Childs, T. H. C., Dalgarno, K. W., Hojjati, M. H. and Tutt, M. J. The meshing of timing belt teeth in pulley grooves. Proc. Instn Mech. Engrs, Part D, Journal of Automobile Engineering, 1997, 211(D3), 205-218.

5 Childs, T. H. C., Hojjati, M. H., Kohno, M. and Nakamura, T. Land friction effects in the meshing of timing belts. Proc. Instn Mech. Engrs, Part J, Journal of Engineering Tribology, 1998, 212(J2), 87-100.

6 Koyama, T., Kagotani, M., Shibata, T. and Hoshiro, T. A study on strength of toothed belts-2nd report. Bull. Jap. Soc. Mech. Engrs, 1979, 22, 982-987.

7 Gerbert, G., Jonsson, H., Persson, U. and Stensson, G. Load distribution in timing belts. Trans. ASME, J. Mech. Des., 1978, 100, 208-215.

8 Naji, M. R. and Marshek, K. M. Toothed belt load distribution. Trans. ASME, J. Mechanisms, 1983, 105, 339-347.

9 Childs, T. H. C. and Parker, I. K. Power transmission by flat, $\mathrm{V}$ and timing belts. In Proceedings of the 15th Leeds-Lyon Symposium on Tribology, Leeds, 1987, pp. 113-142, 1988 (Elsevier, Amsterdam).

10 Karolev, N. A. and Gold, P. W. Load distribution of timing belt drives transmitting variable torque. Mech. Mach. Theory, 1995, 30, 553-567.

11 Frost, N. E., Marsh, K. J. and Pook, L. P. Metal Fatigue, 1974, Section 6.2.2 (Oxford University Press, London).

12 Dalgarno, K. W., Day, A. J., Childs, T. H. C. and Moore, R. B. Stiffness loss of synchronous belts. Composites, Part B, Engng J., 1998, 29B, 217-222.

13 Iizuka, H., Watanabe, K. and Mashimo, S. Observation of fatigue failure in synchronous belts. Fatigue Fracture Engng Mater. Structs, 1994, 17, 783-790.

14 Kido, R., Kusano, T. and Fujii, T. Finite element analysis for distribution of toothed belts in two axes drive system (in Japanese). Trans. Jap. Soc. Mech. Engrs, 1995, 61, 130-136.

15 Parker, I. K. PhD thesis, University of Bradford, Bradford, 1992. 